\title{
MLPA is a practical and complementary alternative to CMA for diagnostic testing in patients with autism spectrum disorders and identifying new candidate CNVs associated with autism
}

\author{
Pavlina Capkova ${ }^{1}$, Josef Srovnal ${ }^{\text {Corresp., }}{ }^{1,2}{ }^{2}$, Zuzana Capkova ${ }^{1}$, Katerina Staffova ${ }^{2}$, Vera Becvarova ${ }^{3}$, Marie \\ Trkova $^{3}$, Katerina Adamova ${ }^{1}$, Alena Santava ${ }^{1}$, Vaclava Curtisova ${ }^{1}$, Marian Hajduch ${ }^{2}$, Martin Prochazka \\ 1 Department of Medical Genetics, University Hospital Olomouc, Olomouc, Czech Republic \\ 2 Institute of Molecular and Translational Medicine, Faculty of Medicine and Dentistry, Palacky University Olomouc, Olomouc, Czech Republic \\ 3 Gennet, s.r.o., Prague, Czech Republic \\ Corresponding Author: Josef Srovnal \\ Email address: josef.srovnal@upol.cz
}

Background: Autism spectrum disorder (ASD) is a complex heterogeneous developmental disease with a significant genetic background that is frequently caused by rare copy number variants (CNV). Microarray-based whole-genome approaches for CNV detection are widely accepted. However, the clinical significance of most CNV is poorly understood, so results obtained using such methods are sometimes ambiguous. We therefore evaluated a targeted approach based on multiplex ligation probedependent amplification (MLPA) using selected probemixes to detect clinically relevant variants for diagnostic testing of ASD patients. We compare the reliability and efficiency of this test to those of CMA and other tests available to our laboratory. In addition, we identify new candidate genes for ASD identified in a cohort of ASD-diagnosed patients.

Method: We describe the use of multiplex ligation probe-dependent amplification (MLPA), chromosomal microarray analysis (CMA), and karyotyping to detect CNV in 92 ASD patients and evaluate their clinical significance.

Result: Pathogenic and likely pathogenic mutations were identified by CMA in $8(8.07 \%$ of the studied cohort) and 12 (13.04 \%) ASD patients, respectively, and in $8(8.07 \%)$ and $4(4.35 \%)$ patients, respectively, by MLPA. The detected mutations include the 22q13.3 deletion, which was attributed to ring chromosome 22 formation based on karyotyping. CMA revealed a total of 91 rare CNV in 55 patients: 8 pathogenic, 15 designated VOUS - likely pathogenic, 10 VOUS - uncertain, and 58 VOUS - likely benign or benign. MLPA revealed 18 CNV in 18 individuals: 8 pathogenic, 4 designated as VOUS- likely pathogenic, and 6 designated as VOUS - likely benign/benign. Rare CNV were detected in 17 (58.62\%) out of 29 females and $38(60.32 \%)$ out of 63 males in the cohort. Two genes, DOCK8 and PARK2, were found to be overlapped by CNV designated pathogenic, VOUS - likely pathogenic, or VOUS - uncertain in multiple patients. Moreover, the studied ASD cohort exhibited significant $(p<0.05)$ enrichment of duplications encompassing DOCK8.

Conclusion: MLPA and CMA yielded concordant results for 12 patients bearing CNV designated pathogenic or VOUS-likely pathogenic. Unambiguous diagnoses were achieved for 8 patients (corresponding to $8.7 \%$ of the total studied population) by both MLPA and CMA, for one (1.09\%) patient by karyotyping, and for one (1.09 \%) patient by FRAXA testing. MLPA and CMA thus achieved identical reliability with respect to clinically relevant findings. As such, MLPA could be useful as a fast and inexpensive test in patients with syndromic autism. The detection rate of potentially pathogenic variants (VOUS - likely pathogenic) achieved by CMA was higher than that for MLPA (13.04 \% vs. $4.35 \%$ ). 
However, there was no corresponding difference in the rate of unambiguous diagnoses of ASD patients. In addition, the results obtained suggest that DOCK8 may play a role in the etiology of ASD. 
1 MLPA is a practical and complementary alternative to CMA for diagnostic testing in patients 2 with autism spectrum disorders and identifying new candidate CNVs associated with autism 3

4 Pavlina Capkova ${ }^{1 \sharp}$, Josef Srovnal ${ }^{1,2^{*}}$, Zuzana Capkova ${ }^{1}$, Katerina Staffova ${ }^{2}$, Vera Becvarova ${ }^{3}$, 5 Marie Trkova ${ }^{3}$, Katerina Adamova ${ }^{1}$, Alena Santava ${ }^{1}$, Vaclava Curtisova ${ }^{1}$, Marian Hajduch ${ }^{2}$ and 6 Martin Prochazka ${ }^{1}$

$8{ }^{1}$ Department of Medical Genetics, University Hospital Olomouc, Czech Republic

92 Institute of Molecular and Translational Medicine, Faculty of Medicine and Dentistry, Palacky 10 University and University Hospital in Olomouc, Czech Republic

$11{ }^{3}$ Gennet, s. r. o., Prague, Czech Republic

$14{ }^{*}$ Corresponding author: Josef Srovnal, MD, PhD, Institute of Molecular and Translational 15 Medicine, Faculty of Medicine and Dentistry, Palacky University and University Hospital in 16 Olomouc, Hnevotinska 5, 77900 Olomouc, Czech Republic, Telephone: +420-58-5632137, Fax:

17 +420-58-5632180, e-mail: josef.srovnal@upol.cz,www.imtm.cz 


\section{Abstract}

Background: Autism spectrum disorder (ASD) is a complex heterogeneous developmental disease

27 with a significant genetic background that is frequently caused by rare copy number variants 28 (CNV). Microarray-based whole-genome approaches for CNV detection are widely accepted.

29 However, the clinical significance of most CNV is poorly understood, so results obtained using such methods are sometimes ambiguous. We therefore evaluated a targeted approach based on multiplex ligation probe-dependent amplification (MLPA) using selected probemixes to detect clinically relevant variants for diagnostic testing of ASD patients. We compare the reliability and efficiency of this test to those of CMA and other tests available to our laboratory. In addition, we 34 identify new candidate genes for ASD that were detected in a cohort of ASD-diagnosed patients.

35 Method: We describe the use of multiplex ligation probe-dependent amplification (MLPA), chromosomal microarray analysis (CMA), and karyotyping to detect CNV in 92 ASD patients and 37 evaluate their clinical significance.

Result: Pathogenic and likely pathogenic mutations were identified by CMA in $8(8.07 \%$ of the studied cohort) and 12 (13.04 \%) ASD patients, respectively, and in $8(8.07 \%)$ and 4 (4.35\%) patients, respectively, by MLPA. The detected mutations include the 22q13.3 deletion, which was

41 attributed to ring chromosome 22 formation based on karyotyping. The FMR1 mutation was

42 detected in one patient. CMA revealed a total of 91 rare CNV in 55 patients: 8 pathogenic, 15 designated VOUS - likely pathogenic, 10 VOUS - uncertain, and 58 VOUS - likely benign or benign. 
44 MLPA revealed 18 CNV in 18 individuals: 8 pathogenic, 4 designated as VOUS- likely pathogenic, 45 and 6 designated as VOUS - likely benign/benign. Rare CNV were detected in 17 (58.62 \%) out of 4629 females and $38(60.32 \%)$ out of 63 males in the cohort. Two genes, DOCK 8 and PARK2, were 47 found to be overlapped by CNV designated pathogenic, VOUS - likely pathogenic, or VOUS 48 uncertain in multiple patients. Moreover, the studied ASD cohort exhibited significant $(p<0.05)$ 49 enrichment of duplications encompassing DOCK8.

50 Conclusion: MLPA and CMA yielded concordant results for 12 patients bearing CNV designated 51 pathogenic or VOUS-likely pathogenic (corresponding to $60 \%$ of the study population exhibiting 52 such (NV), including a ring chromosome 22. Unambiguous diagnoses were achieved for 8 patients 53 (corresponding to $8.7 \%$ of the total studied population) by both MLPA and CMA, for one (1.09\%) 54 patient by karyotyping, and for one (1.09\%) patient by FRAXA testing. MLPA and CMA thus 55 achieved identical reliability with respect to clinically relevant findings. As such, MLPA could be 56 useful as a fast and inexpensive test in patients with syndromic autism. The detection rate of 57 potentially pathogenic variants (VOUS - likely pathogenic) achieved by CMA was significantly higher than that for MLPA (13.04 \% vs. $4.35 \%)$. However, there was no corresponding difference

59 in the rate of unambiguous diagnoses of ASD patients. In addition, the results obtained suggest 60 that DOCK8 may play a role in the etiology of ASD.

\section{Introduction}

62 Autistic spectrum disorders (ASD) are complex heterogeneous developmental diseases with a 63 significant genetic background and include three closely related diagnoses: autistic disorder, 64 Asperger syndrome, and pervasive developmental disorder - not otherwise specified (PDD-NOS). 65 They are characterized by simultaneous deficits in 3 domains of behavior: reciprocal social 
66 interaction, communication, and stereotyped and restricted behaviors. Their estimated

67 prevalence in the population is 1:68, with males being predominantly affected (McCarthy, 2014;

68 de la Torre-Ubieta et al., 2016; Schaefer, 2016; Schaefer \& Mendelsohn, 2013; Miller et al., 2010).

69 ASD occurs frequently with the following comorbidities: a motor deficit, sleep abnormalities,

70 gastrointestinal disturbances, epilepsy, and intellectual disability (de la Torre-Ubieta et al., 2016;

71 Schaefer, 2016). These comorbidities can also overlap with phenotypes observed in other

72 neuropsychiatric disorders.

73 Submicroscopic copy number variants (CNV) may have a causal or susceptibility-related role in

74 the heritability of ASD. However, the causality and/or pathogenicity of these CNV is largely

75 unknown due to their variable expression and incomplete penetrance, which can result in a

76 spectrum of phenotypes ranging from asymptomatic to intellectual disability (ID)/developmental

77 delay (DD)/ASD. Many studies have sought to identify new candidate genes for ASD but fewer

78 have sought to clarify their clinical significance for patients and their families. Chromosomal

79 microarrays (CMAs) were recently identified as a first-tier method for testing in patients with

80 ID/DD/ASD (Schaefer, 2016; Schaefer \& Mendelsohn, 2013; Miller et al., 2010; South et al., 2013).

81 However, little is currently known about the clinical significance of most CNV, which can hamper

82 the interpretation of test results and complicate genetic counseling. Unlike CMA, multiplex

83 ligation-dependent probe amplification (MLPA) is fast and provides easily interpreted results. It

84 can therefore serve as a clinically effective targeted test to detect recurrent CNV associated with

85 ASD, and is currently used as a preliminary test to exclude recurrent pathogenic CNV in our 86 department. 
87 This study compares the efficiency and reliability of MLPA and CMA in diagnostic testing of ASD

88 patients. A secondary objective was to identify new candidate genes for ASD. We present results

89 obtained by using a combination of MPLA and CMA to analyze CNV in a cohort of 92 children

90 diagnosed with ASD.

\section{Materials and Methods}

\section{Participants}

93 The study involved 92 individuals of Caucasian ethnicity - 63 males and 29 females - with autism

94 (54), PDD-NOS (35) and Asperger syndrome (3), predominantly from simplex families (89\%).

95 These patients were referred to genetic counselling solely on the basis of an ASD, PDD-NOS, or

96 Asperger syndrome diagnosis, or based on some level of neurodevelopmental impairment

97 together with ASD or PDD-NOS. The size of the study population is approximately $1 / 5^{\text {th }}$ of the

98 number of child patients that undergo genetic testing in our department each year. Patients with

99 known monogenic syndromes (e.g. familial cases and clear syndromic cases) associated with ASD

100 (tuberose sclerosis, neurofibromatosis, etc.) were excluded. Peripheral blood samples were

101 collected after genetic counseling in the Department of Medical Genetics at the University

102 Hospital in Olomouc, Czech Republic, during the years 2012-2016. For 17 patients, the DNA of

103 both parents was obtained to verify the origin of the detected variants. The study was approved

104 by the Institutional Review Board of the University Hospital and Faculty of Medicine and Dentistry,

105 Palacky University, Olomouc (IRB number 96/17). All procedures were conducted in accordance

106 with the Declaration of Helsinki. Written informed consent for the use of personal particulars and

107 genetic information for research purposes was collected from the patients' parents or guardians

108 during genetic counselling. The cohort's mean age at evaluation was $5.0 \pm 2.9$ years. 
109 The patients underwent rigorous examinations by pediatricians, neurologists, psychiatrists and

110 geneticists, including metabolic tests and brain imaging. Individuals were diagnosed with ASD by

111 clinicians after performing the Autism Diagnostic Interview-Revised and Autism Diagnosis

112 Observation Schedule. The subjects with pervasive developmental disorders and varying levels of

113 impairment were diagnosed with broad-spectrum disorder, which includes conditions such as

114 pervasive developmental disorder not otherwise specified (PDD-NOS) and Asperger syndrome.

115 Phenotype descriptions for patients with pathogenic/VOUS - likely pathogenic and VOUS -

116 uncertain findings are presented in the Supplemental file. The frequency of CNV overlapping the

117 DOCK8 gene in the healthy population was determined by MLPA analysis (using the SALSA MLPA

118 P385-A2 DOCK8 probemix) of 40 male and 40 female control individuals exhibiting no related

119 health conditions.

\section{Study design}

122 The study used a retrospective observational design.

\section{Methods}

125 Systematic screening for pathogenic mutations was performed by karyotyping, fragile X syndrome

126 testing, screening for metabolic disorders, targeted MLPA testing, and CMA. Cytogenetic analysis

127 was performed using cultured lymphocytes by conventional G-banding with a resolution of 550

128 bphs. DNA was isolated from peripheral blood by the saline method. DNA samples were tested

129 for the FMR1 mutation by PCR using fluorescently labelled primers as described previously (Zhou,

130 2006). MLPA tests were performed with SALSA ${ }^{\circledR}$ MLPA $^{\circledR}$ sets P070-B3 and P036-E3 (the 
131 Subtelomeres Mix 1 and Mix 2B probemixes), P245-B1 and P297-B2/C1 (the Microdeletions 1A

132 and 2 probemixes), P343-C3 (the Autism1 probemix), and P106-C1 (the Mental retardation X-

133 linked probemix) in accordance with the manufacturer's protocol. The Coffalyser program was

134 used for CNV calling (MRC-Holland, Amsterdam, Netherlands). PCR products were identified and

135 quantified by capillary electrophoresis on an ABI 3130 genetic analyzer, using the Gene Mapper

136 software from Applied Biosystems, Foster City, CA. Other MLPA probemixes (P051/P052-D1 and

137 P385-A2) were used to verify CMA findings relating to PARK2 and DOCK8.

138 Chromosomal microarray analyses were performed using a Cytoscan HD (Affymetrix, Santa Clara,

139 CA, USA) or CytoSNP-12(Illumina, San Diego, CA, USA) instrument according to the

140 manufacturer's protocol. The data discussed in this publication have been deposited in NCBI's

141 Gene Expression Omnibus database (Edgar, Domrachev \& Lash, 2002) and are accessible using 142 GEO Series $\quad$ accession $\quad$ number $\quad$ GSE114870

143 (https://www.ncbi.nlm.nih.gov/geo/query/acc.cgi?acc=GSE114870). The programs CHAS v. 1.2.2

144 and Illumina KaryoStudio 1.3 from Genome Studio V2011.1 were used for CNV calling. The

145 observed CNV were compared to CNV recorded in the DGV to assess their frequency in the

146 population. CNV encompassing coding regions with frequencies of $<1 \%$ in the population were

147 considered rare variants. The clinical significance of individual CNV was evaluated according to

148 the ACMG Standard and Guidelines (Kearney et al., 2011). Where possible, parental samples were

149 collected for patients exhibiting pathogenic CNV and variants of unknown significance (VOUS) to

150 determine the CNV's origin. Detected CNV were systematically compared to CNV recorded in

151 curated databases (ISCA, DECIPHER, SFARI, and DGV) to determine their clinical significance.

152 Fisher's exact test was used to calculate the statistical significance of the frequency of DOCK 8 
153 duplication in the ASD population (www.socscistatistics.com/tests/fisher/Default2.aspx). As a

154 control, we used data from population sequencing studies held by the 1000 Genomes Consortium

155 (Mills et al., 2011).

\section{Results}

157 Karyotyping revealed chromosomal aberrations in 3 (3.26 \%) patients from the cohort: 1

158 pathogenic $r(22)(q 13.3)(1.08 \%)$ and 2 likely benign $t(10 ; 11)(q 26 ; p 13)$ pat, $\operatorname{inv}(Y)(p 11.2 q 11.23)$

159 (Table 1). The FMR1 mutation was identified in 1 (1.09\%) individual. In total, MLPA revealed 18

160 CNV in 18 (19.57\%) individuals: 8 (44.44\%) pathogenic (including a terminal deletion in ring

161 chromosome 22), 4 (22.22 \%) designated as VOUS- likely pathogenic and confirmed by CMA, and

$1626(33.33 \%)$ designated as VOUS - likely benign/benign. All but 3 of these detected variants were

163 confirmed by CMA. The variants not confirmed by CMA were small deletions (MAPK3- pat inherit.,

164 SNRPN - mat inherit., FRG1- pat inherit.) identified using one probe; these deletions probably

165 correspond to SNV that were inherited from healthy parents and lie in the probe's hybridization

166 region. This phenomenon has been described previously and represents an inherent limitation of

167 MLPA (Cai et al., 2008).

168 CMA identified 91 rare CNV (60 duplications and 31 deletions) that contained coding regions and

169 had MAF values of < $1 \%$ in $55(59.78 \%)$ patients. Among these were $8(8.79 \%)$ pathogenic CNV,

17015 (16.48 \%) CNV designated as VOUS - likely pathogenic, 10 (10.99\%) designated as VOUS -

171 uncertain, and 58 (63.73\%) designated as VOUS - likely benign or benign (Table 2). The

172 percentages of rare CNV in the males (60.32\%) and females (58.62\%) of our cohort were similar.

173 MLPA and CMA yielded concordant results for all eight patients $(8.7 \%$ of the study cohort)

174 exhibiting pathogenic mutations. CNV designated VOUS - likely pathogenic were identified as 
175 primary CMA findings in 12 individuals ( $13.04 \%$ of the cohort), but only 4 (4.35\%) of these were

176 also discovered by MLPA (Table 1). The rate of detection for CNV designated as VOUS - likely

177 pathogenic when using CMA was thus 8.69 percentage points higher than that achieved using

178 MLPA. This difference was significant $(p=0.039)$. These CNV represent potentially harmful

179 mutations but there is currently insufficient evidence to classify them as being causal of the

180 patient's disorder. The rate of pathogenic variant detection using MLPA and CMA was 7.61

181 percentage points higher than that achieved by karyotyping alone in the cohort of ASD patients.

182 A terminal deletion of chromosome 22 affecting the gene SHANK3 was detected by all methods

183 in the patient with ring chromosome 22. However, without karyotyping, this deletion's

184 mechanism of occurrence would not have been determined. The duplication 15q11.2q13.1

185 (patient 1522/16) was identified as a chromosome heteromorphism during cytogenetic

186 assessment, but both MLPA and CMA revealed the duplication.

187 Eight recurrent CNV known to be associated with ASD were found in our cohort - deletions 7q11.2

188 (Williams-Beuren Syndrome; WBS), 22q11.2 (Velocardiofacial Syndrome;VCFS), 22q13 (Phelan-

189 McDermid Syndrome), 16p11.2, and Xp21.2-p21.1 (Becker muscular dystrophy; BMD); and

190 duplications 1q21.1, 16p11.2, and 15q11-q13 (Table 2A). Several CNV encompassed genes

191 reported to be important in the etiology of autism or schizophrenia (APOO, ARX, TSPAN7, NRXN1,

192 CSMD1, CTNNA3, RBFOX1, MACROD2, ASMT, DISC1, PARK2, DOCK8); these CNV were designated

193 "likely pathogenic" because they are listed in curated databases (SFARI) or have repeatedly been

194 identified as being involved in the etiology of autism or intellectual disability (Table 2B).

195 Recurrent duplications (9p24.3) overlapping the DOCK8 gene (specifically, spanning exons 1-2, 2-

196 43, and 1-26) were detected in 3 unrelated patients by MLPA and CMA (Figure 1). All of these 
197 duplications are currently recorded as variants of unknown clinical significance. A similar MLPA

198 analysis of a control cohort of 80 healthy individuals revealed no individuals with CNV

199 encompassing this gene. Moreover, DOCK8 gain variants were found in only 12 of the 2504

200 healthy individuals whose genetic data was published by the 1000 Genomes Consortium (Mills et

201 al., 2011). DOCK8 gain variants are thus significantly enriched in the ASD cohort relative to the 202 population as a whole $(p<0.05)$.

203 We also analyzed the phenotypes of patients with similar duplications encompassing the gene 204 DOCK8 that have been reported in the literature and the ISCA and Decipher databases (Table 3).

205 The analyzed cases exhibited similar phenotypes involving ASD, DD, speech delay seizures, 206 dysmorphic features and behavioral abnormalities. Additional phenotypes observed in our 207 patients with DOCK8 duplications include hearing impairment and attention hyperactivity 208 disorder (ADHD), which was also reported previously by Glessner (Glessner et al., 2017). Our 209 patients also exhibited undescended testes (2) and atrophy of one testis (1).

210 Ten CNV with uncertain significance were found in the cohort (Table 2C). This category included

211 variants that lack entries in the DGV but contained brain-expressed and/or dosage-sensitive

212 genes, such as dup11q14-q21, which spans melatonin receptor 1B (MTNR1B) and fat tumor

213 suppressor 3 (FAT3); del 6q22, which spans protein-tyrosine phosphatase, receptor-type, kappa

214 (PTPRK); dup 17q21.31, which spans granulin (GRN) and run domain-containing protein 3A 215 (RUNDC3A); and dup 9q33.2, which spans stomatin (STOM) and gelsolin (GSN). The category also

216 included variants with entries in the DGV that span brain-expressed dosage-sensitive genes for 217 which there is little or no evidence of involvement in the etiology of autism. CNV in this latter 218 group were del 2p12, which spans catenin, alpha-2 (CTNNA2); dup 16q11.2, which spans vacuolar 
219 protein sorting 35 (VSP35); and dup Xp11.22, which spans (SMC1A) and 17-beta-hydroxysteroid

220 dehydrogenase $\mathrm{X}$ (HSD17B10). Other CNV in this group included variants overlapping OMIM

221 morbid genes associated with etiologies for non-neuropsychiatric disorders, namely dup 5q32.3,

222 del 2q13, and dup 16p12.2, spanning muscle segment homeobox 2 (MSX2), nephrocystin 1

223 (NPHP1), and otoancorin (OTOA), respectively.

224 Three patients exhibited multiple CNV designated as pathogenic, likely pathogenic, or VOUS-

225 uncertain: D1377/15, D1190/16 and D1094/16 (Tab 2B, 2C).

226 Interestingly, secondary findings, i.e. CNV encompassing genes of interest (here defined as genes

227 associated with autism or expressed in the brain), were discovered in the patient with the FMR1

228 mutation. One of these CNV encompassed the genes ASMT, and the other encompassed

229 HSD17B10 and SMC1A. A paternally inherited deletion/SNV involving the MAPK3 gene (16p11.2

230 region) detected by MLPA was also identified in this patient.

231 CNV encompassing genes involved in the pathophysiology of parkinsonism were detected in 3

232 (3.26\%) patients. A deletion (covering exons 2 - 3) and a duplication (covering exon 2) of the gene

233 PARK2 (6q26) were discovered in two unrelated patients, and duplication of 16q11.2 including

234 the gene VSP35 (PARK17) was discovered in the third.

\section{Discussion}

236 The detection rate for pathogenic CNV in ASD patients achieved using MLPA was identical to that

237 achieved using CMA. We therefore suggest that MLPA is sufficient to diagnose unambiguously

238 pathogenic variants under some circumstances - for instance, when CMA is unavailable or in cases

239 where the need to interpret VOUS variants or incidental findings would be problematic and

240 patients would be unwilling to deal with the implications of such variants being detected 
241 (especially in cases where a prenatal genetic diagnosis would have to be followed up with further

242 investigations within the family). The patients would retain the ability to refuse to be informed of

243 such findings despite their possible pathogenic impact; in such cases, CMA would be redundant

244 because we have confirmed that clinically significant variants can be detected by both methods.

245 This example demonstrates that the benefits of CMA in clinical applications differ from those in

246 research contexts, and shows that CNV analysis by CMA in individuals with ASD can enable

247 diagnosis and appropriate genetic counseling in a small number of cases. CMA is unavailable to

248 some laboratories because it requires specialized equipment. Therefore, many labs would have

249 to make a large capital outlay to perform CMA but will be readily able to perform MLPA with

250 existing equipment to determine the causes of known syndromes. These laboratories can rely on

251 targeted methods such as MLPA to exclude possible causes of syndromic autism. However, MLPA

252 would not be sufficient to detect CNV associated with nonsyndromic ASD. Therefore, CMA

253 remains an invaluable tool for studying the causes of ASD. Our results confirm that CMA

254 outperforms MLPA at detecting CNV classified as VOUS - likely pathogenic. These variants can

255 help reveal new genes involved in the emergence of ASD. Most ASD patients with detected

256 pathogenic CNV are classified as having syndromic autism because the diagnosis of ASD is usually

257 secondary to developmental delay or intellectual disability with further comorbidities such as

258 dysmorphic features or growth delay that may suggest the involvement of a syndrome based on

259 the procedures adopted here (see Supplemental files). Although all the patients in the studied

260 cohort had been assessed by a genetic counsellor before the study was conducted, none of them

261 had been suggested to have any syndrome prior to our testing. This could be partly due to the

262 phenotypic variability of some syndromes. 
263 Even in the boy with BMD, the diagnosis of the syndrome was based on MLPA testing and

264 subsequent confirmation by targeted DNA analysis at 12 years of age. However, the primary

265 reasons given when referring this patient for genetic investigation were severe growth delay,

266 dystrophia together with autistic features. Because the patient's dystrophia was milder than in

267 DMD, the case was classified as BMD. The typical VCFS phenotype did not manifest in the patient

268 with microdeletion 22q11.2 because the deleted interval did not include the TBX1 or HIRA genes

269 - the deletion was rather distal, spanning the ASD candidate gene LZTR1 (Krumm et al., 2015).

270 The distal microdeletion 22 q11.2 has been linked to behavioral and psychiatric impairments

271 (Burnside, 2015). In the patient with ring chromosome 22, MLPA confirmed the suspected loss of

272 the terminal part of chromosome 22 and the loss of the SHANK3 gene, which has been associated

273 with ASD (Durand et al., 2007; Nemirovsky et al., 2015). These findings explained the patient's

274 phenotype and resulted in a diagnosis of Phelan-McDermid syndrome. The most notable aspects

275 of the patient's phenotype were severe developmental delay and neuropsychiatric impairment

276 (recently described as low functioning autism). However, at the age (24 months) when the girl

277 was tested, the syndrome's hallmarks had not fully manifested. Further testing was required in 4

278 patients with CNV VOUS - likely pathogenic and 6 patients with CNV VOUS - likely benign or

279 benign because there may have been pathogenic CNV outside the loci covered by the tested

280 probemixes in these cases. The detection rate of MLPA depends somewhat on the chosen

281 probemix, but is comparable to that for CMA if one restricts one's focus to clinically well described

282 recurrent pathogenic CNV. This makes MLPA a convenient method for fast, reliable, and

283 inexpensive targeted exclusion of CNV involved mostly in syndromic autism. The detection rate

284 for pathogenic or likely pathogenic CNV by CMA in ASD patients ranges from $3-30 \%$ depending 
285 on the cohort and acceptance criteria (Nava et al., 2013; Wang et al., 2016; Guo et al., 2017; Shen

286 et al., 2010; Bremer et al., 2011; Cappuccio et al., 2016; Leppa et al., 2016). In this work, CMA

287 revealed 8 index cases with pathogenic CNV. This result is comparable to previous reports (Nava

288 et al., 2013; Shen et al., 2010; Bremer et al., 2011). CMA achieved a higher detection rate for

289 potentially pathogenic variants than MLPA or karyotyping in this work. However, without

290 karyotyping it would have been very difficult to determine the mechanism of occurrence of

291 deletion 22q13.33 (which was due to ring 22). Nor would we have detected the balanced

292 chromosomal rearrangements in two patients. The possibility that these rearrangements may

293 have contributed to the etiology of ASD in these patients cannot be completely excluded.

294 We observed a relatively high frequency of CNV encompassing genes associated with

295 parkinsonism in our group of ASD patients. Variants encompassing PARK2 have previously been

296 detected in ASD patients (Nava et al., 2013; Yin et al., 2016). However, we also detected a CNV

297 involving VSP35 (PARK17) in one of our patients whose genome contained multiple CNV. This

298 gene has been suggested to play a role in parkinsonism (Zimprich et al., 2011). The relatively high

299 frequency of CNV overlapping genes associated with this disease raises the possibility that these

300 patients may have an elevated risk of developing parkinsonism in adulthood. An increased

301 frequency of parkinsonism among ASD patients has previously been reported (Starkstein et al.,

302 2015). However, the role of parkinsonism-related genes in the etiology of ASD is currently unclear.

303 It is possible that different kinds of genomic changes affecting certain genes can lead to different

304 phenotypes (Scheuerle \& Wilson, 2011).

305 Two patients exhibited variants encompassing two melatonin-related genes: acetylserotonin O-

306 methyltransferase (ASMT) and the melatonin receptor (MNTR1B). Both genes have been 
307 identified as potentially affecting the risk of ASD (Cai et al., 2008; Nava et al., 2013; Jonsson et al.,

308 2010; Anderson et al., 2009). The duplication region 11q14.3-q21 encompassing MNTR1B and

309 FAT3 cooccurred with duplication Xq27.3 encompassing the SOX3 gene, which was previously

310 linked to the etiology of ID, hypopituitarism, and speech disorders, but not ASD (Solomon, 2004;

311 Stankiewicz et al., 2005).

312 Two patients exhibited variants overlapping genes encoding catenins (cadherin-associated

313 proteins): deletion 10q21.3 overlaps catenin alpha 3 (CTNNA3), and deletion 2p12 overlaps

314 catenin alpha 2 (CTNNA2). The first CTNNA3 deletion cooccurred with other CNV - deletion

315 8p23.2 (CSMD1), duplication 16q11.2 (VSP35), and duplication 1q42.2 (DISC1). While variations

316 in CTNNA3 have been described in patients with ASD, variations in CTNNA2 have not (Folmsbee

317 et al., 2016; Bacchelli et al., 2014). CTNNA2 is predominantly expressed in the brain and helps

318 regulate the stability of synaptic contacts and axogenesis, brain morphogenesis, dendrite

319 morphogenesis, and synapse structural plasticity (www.uniprot.org), making it a plausible

320 candidate for involvement in the etiology of ASD.

321 Duplications covering the gene DOCK8 were identified in multiple patients by both MLPA and

322 CMA. DOCK8 encodes a member of the Dock protein family of atypical Rho guanine nucleotide

323 exchange factors (GEFs) for Rac and/or Cdc42 GTPases that play pivotal roles in various processes

324 of brain development. To date, 11 members of the Dock family have been identified in mammals.

325 Dock proteins regulate the actin cytoskeleton, cell adhesion and dendritic migration (Gadea \&

326 Blangy, 2014). There is also evidence that members of the Dock family are associated with several

327 neurodegenerative and neuropsychiatric diseases, including Alzheimer's disease and ASD (Shi,

328 2014). Homozygous loss of function of the DOCK8 gene causes Autosomal Recessive Hyper-IgE 
329 Recurrent Infection Syndrome (Zhang et al., 2009). In addition, evidence was recently presented

330 supporting a causal relationship between heterozygous disruption of DOCK8 and mental

331 retardation, pervasive developmental disorders, autism, and bipolar disorders (Nava et al., 2013;

332 Wang et al., 2016; Griggs et al., 2008; Glessner et al., 2017; Krgovic et al., 2018;). Our results

333 support the findings of Glessner et al., who identified DOCK8/KANK1 as novel significant loci for

334 ASD and ADHD (Glessner et al., 2017). We observed significant enrichment of CNV involving gains

335 of the DOCK8 gene in the studied ASD cohort. This may indicate that the region of the

336 DOCK8/KANK1 locus associated with ASD and ADHD is likely to be within or proximal to the gene

337 DOCK8. Our patients with DOCK8 gains had all been diagnosed with ADHD. We detected no

338 individuals with any CNV overlapping with the DOCK8 gene in our control cohort, so we regard

339 this gene as an interesting candidate for further study on the etiology of ASD. Because the DOCK8

340 duplication was inherited from a healthy father in one case, we assume that variant increases the

341 risk of ASD or other neuropsychiatric conditions but that its phenotypic impact may be limited by

342 incomplete penetrance or/and variable expressivity. Both of these factors are known to

343 complicate genetic counselling in patients with CNV encompassing neurosusceptibility loci.

344 The greatest limitation of this study, aside from the relatively small cohort, is the lack of

345 information about the inheritance of most of the identified CNV. It seems that CNV with variable

346 expressivity (del/dup16p11.2, NRXN1) are frequently inherited. An analysis of ASD patients'

347 parental genomes could thus help to explain the patients' phenotypes. A segregational analysis

348 was performed for the family with a heterozygotic loss in NRXN1, revealing that this CNV

349 exhibited incomplete penetrance (Figure 2).

350 


\section{Conclusion}

352 Diagnosis was achieved in only 8 index cases ( $8.7 \%$ of the studied cohort), all of which involved

353 patients classified as having syndromic autism. The rate of pathogenic CNV detection by CMA was

354 identical to that achieved with MLPA using probemixes targeted towards losses associated with

355 ID, DD, and ASD. Consequently, our results indicate that MLPA and CMA are equally reliable 356 methods for obtaining clinically relevant findings. Therefore, MLPA can be used as a quick

357 alternative to CMA for excluding syndromes associated with ASD. MLPA is also frequently used to 358 confirm CMA findings, and for targeted verification of the origins of CNV during parental testing.

359 However, many genes are involved in the etiology of ASD, creating a clear need for whole-genome

360 screening to identify genes associated with ASD and to clarify the clinical impact of VOUS.

361 Moreover, increasing knowledge of knew candidate genes in ASD provided by CMA (or NGS)

362 enables to develop the new targeted tests (MLPA probemixes, targeted arrays) for quick exclusion

363 known pathogenic mutations in particular patients. Our results confirm that traditional

364 karyotyping is an indispensable tool for deciphering the origins of specific CNV and detecting

365 balanced chromosomal changes, the clinical significance of which cannot be totally disregarded

366 in ASD patients. This work presents further evidence that genes identified in the etiology of

367 various genetic conditions can be linked to the pathophysiology of ASD (DOCK8). However, the

368 exact pathophysiological mechanism underlying the functions of these genes in the development

369 of phenotypes such as ASD remains unknown.

370 Abbreviations

ASD Autism spectrum disorders 


$\begin{array}{ll}\text { PDD-NOS } & \text { Pervasive developmental disorder - not otherwise specified } \\ \text { MLPA } & \text { Multiplex ligation probe-dependent amplification } \\ \text { CMA } & \text { Chromosomal microarray analysis } \\ \text { CNV } & \text { Copy number variants } \\ \text { VOUS } & \text { Variant of unknown significance } \\ \text { ID } & \text { Intellectual disability } \\ \text { DD } & \text { Developmental delay }\end{array}$

371

372 References

373 Anderson BM., Schnetz-Boutaud NC., Bartlett J., Wotawa AM., Wright HH., Abramson RK., 374 Cuccaro ML., Gilbert JR., Pericak-Vance MA., Haines JL. 2009. Examination of association of genes 375 in the serotonin system to autism. Neurogenetics 10:209-216 DOI: 10.1007/s10048-009-0171-7. 376

377 Bacchelli E., Ceroni F., Pinto D., Lomartire S., Giannandrea M., D'Adamo P., Bonora E., Parchi P., 378 Tancredi R., Battaglia A., Maestrini E. 2014. A CTNNA3 compound heterozygous deletion 379 implicates a role for $\alpha \mathrm{T}$-catenin in susceptibility to autism spectrum disorder. Journal of 380 Neurodevelopmental Disorders 6:17 DOI: 10.1186/1866-1955-6-17.

381

382 Bremer A., Giacobini MB., Eriksson M., Gustavsson P., Nordin V., Fernell E., Gillberg C., Nordgren 383 A., Uppströmer Å., Anderlid B-M., Nordenskjöld M., Schoumans J. 2011. Copy number variation 
384 characteristics in subpopulations of patients with autism spectrum disorders. American Journal

385 of Medical Genetics Part B: Neuropsychiatric Genetics 156:115-124 DOI: 10.1002/ajmg.b.31142.

386

387 Burnside RD. 2015. 22q11.21 Deletion Syndromes: A Review of Proximal, Central, and Distal

388 Deletions and Their Associated Features. Cytogenetic and Genome Research 146:89-99 DOI:

$389 \quad 10.1159 / 000438708$.

390

391 Cai G., Edelmann L., Goldsmith JE., Cohen N., Nakamine A., Reichert JG., Hoffman EJ., Zurawiecki

392 DM., Silverman JM., Hollander E., Soorya L., Anagnostou E., Betancur C., Buxbaum JD. 2008.

393 Multiplex ligation-dependent probe amplification for genetic screening in autism spectrum

394 disorders: Efficient identification of known microduplications and identification of a novel

395 microduplication in ASMT. BMC Medical Genomics 1:50 DOI: 10.1186/1755-8794-1-50.

396

397 Cappuccio G., Vitiello F., Casertano A., Fontana P., Genesio R., Bruzzese D., Ginocchio VM.,

398 Mormile A., Nitsch L., Andria G., Melis D. 2016. New insights in the interpretation of array-CGH:

399 autism spectrum disorder and positive family history for intellectual disability predict the

400 detection of pathogenic variants. Italian Journal of Pediatrics 42:39 DOI: 10.1186/s13052-016-

$401 \quad 0246-7$.

402

403 Chiocchetti AG., Bour HS., Freitag CM. 2014. Glutamatergic candidate genes in autism spectrum

404 disorder: an overview. Journal of Neural Transmission 121:1081-1106 DOI: 10.1007/s00702-014405 1161-y. 
407 Deardorff MA., Kaur M., Yaeger D., Rampuria A., Korolev S., Pie J., Gil-Rodríguez C., Arnedo M., 408 Loeys B., Kline AD., Wilson M., Lillquist K., Siu V., Ramos FJ., Musio A., Jackson LS., Dorsett D., 409 Krantz ID. 2007. Mutations in Cohesin Complex Members SMC3 and SMC1A Cause a Mild Variant 410 of Cornelia de Lange Syndrome with Predominant Mental Retardation. The American Journal of 411 Human Genetics 80:485-494 DOI: 10.1086/511888.

412

413 Decipher https://decipher.sanger.ac.uk

415 Durand CM., Betancur C., Boeckers TM., Bockmann J., Chaste P., Fauchereau F., Nygren G., 416 Rastam M., Gillberg IC., Anckarsäter H., Sponheim E., Goubran-Botros H., Delorme R., Chabane 417 N., Mouren-Simeoni M-C., de Mas P., Bieth E., Rogé B., Héron D., Burglen L., Gillberg C., Leboyer 418 M., Bourgeron T. 2007. Mutations in the gene encoding the synaptic scaffolding protein SHANK3 419 are associated with autism spectrum disorders. Nature Genetics 39:25-27 DOI: 10.1038/ng1933. 420

421 Edgar R., Domrachev M., Lash AE. 2002. Gene Expression Omnibus: NCBI gene expression and 422 hybridization array data repository. Nucleic Acids Research 30:207-10 DOI: 423 10.1093/nar/30.1.207.

425 Folmsbee SS., Wilcox DR., Tyberghein K., De Bleser P., Tourtellotte WG., van Hengel J., van Roy 426 F., Gottardi CJ. 2016. AT-catenin in restricted brain cell types and its potential connection to 427 autism. Journal of Molecular Psychiatry 4:2 DOI: 10.1186/s40303-016-0017-9. 
429 Froyen G., Corbett M., Vandewalle J., Jarvela I., Lawrence O., Meldrum C., Bauters M., Govaerts 430 K., Vandeleur L., Van Esch H., Chelly J., Sanlaville D., van Bokhoven H., Ropers H-H., Laumonnier

431 F., Ranieri E., Schwartz CE., Abidi F., Tarpey PS., Futreal PA., Whibley A., Raymond FL., Stratton 432 MR., Fryns J-P., Scott R., Peippo M., Sipponen M., Partington M., Mowat D., Field M., Hackett A., 433 Marynen P., Turner G., Gécz J. 2008. Submicroscopic Duplications of the Hydroxysteroid 434 Dehydrogenase HSD17B10 and the E3 Ubiquitin Ligase HUWE1 Are Associated with Mental 435 Retardation. The American Journal of Human Genetics 82:432-443 DOI: 436 10.1016/j.ajhg.2007.11.002.

438 Gadea G., Blangy A. 2014. Dock-family exchange factors in cell migration and disease. European 439 Journal of Cell Biology 93:466-477 DOI: 10.1016/j.ejcb.2014.06.003.

441 Glessner JT., Li J., Wang D., March M., Lima L., Desai A., Hadley D., Kao C., Gur RE., Cohen N., 442 Sleiman PMA., Li Q., Hakonarson H. 2017. Copy number variation meta-analysis reveals a novel 443 duplication at 9p24 associated with multiple neurodevelopmental disorders. Genome 444 Medicine 9:106 DOI: 10.1186/s13073-017-0494-1.

446 Griggs BL., Ladd S., Saul RA., DuPont BR., Srivastava AK. 2008. Dedicator of cytokinesis 8 is 447 disrupted in two patients with mental retardation and developmental disabilities. Genomics 448 91:195-202 DOI: 10.1016/j.ygeno.2007.10.011. 
450 Guo H., Peng Y., Hu Z., Li Y., Xun G., Ou J., Sun L., Xiong Z., Liu Y., Wang T., Chen J., Xia L., Bai T.,

451 Shen Y., Tian Q., Hu Y., Shen L., Zhao R., Zhang X., Zhang F., Zhao J., Zou X., Xia K. 2017. Genome-

452 wide copy number variation analysis in a Chinese autism spectrum disorder cohort. Scientific

453 Reports 7:44155 DOI: 10.1038/srep44155.

454

455 ISCA http://dbsearch.clinicalgenome.org/search/

456

457 Jonsson L., Ljunggren E., Bremer A., Pedersen C., Landén M., Thuresson K., Giacobini MB., Melke

458 J. 2010. Mutation screening of melatonin-related genes in patients with autism spectrum

459 disorders. BMC Medical Genomics 3:10 DOI: 10.1186/1755-8794-3-10.

460

461 Kearney HM., Thorland EC., Brown KK., Quintero-Rivera F., South ST. 2011. American College of

462 Medical Genetics standards and guidelines for interpretation and reporting of postnatal

463 constitutional copy number variants. Genetics in Medicine 13:680-685 DOI:

464 10.1097/GIM.0b013e3182217a3a.

465

466 Krgovic D., Kokalj Vokac N., Zagorac A., Gregoric Kumperscak H. 2018. Rare structural variants in 467 the DOCK8 gene identified in a cohort of 439 patients with neurodevelopmental 468 disorders. Scientific Reports 8:9449 DOI: 10.1038/s41598-018-27824-0. 
470 Krumm N., Turner TN., Baker C., Vives L., Mohajeri K., Witherspoon K., Raja A., Coe BP., Stessman

471 HA., He Z-X., Leal SM., Bernier R., Eichler EE. 2015. Excess of rare, inherited truncating mutations

472 in autism. Nature Genetics 47:582-588 DOI: 10.1038/ng.3303.

473

474 Leppa V M., Kravitz S N., Martin C L., Andrieux J., Le Caignec C., Martin-Coignard D., DyBuncio C.,

475 Sanders S J., Lowe J K., Cantor R M., Geschwind D H. 2016. Rare Inherited and De Novo CNVs

476 Reveal Complex Contributions to ASD Risk in Multiplex Families. The American Journal of Human

477 Genetics 99:540-554DOI: 10.1016/j.ajhg.2016.06.036.

478

479 McCarthy M. 2014. Autism diagnoses in the US rise by 30\%, CDC reports. BMJ 348:g2520-g2520

480 DOI: $10.1136 /$ bmj.g2520.

481

482 Miller DT., Adam MP., Aradhya S., Biesecker LG., Brothman AR., Carter NP., Church DM., Crolla 483 JA., Eichler EE., Epstein CJ., Faucett WA., Feuk L., Friedman JM., Hamosh A., Jackson L., Kaminsky 484 EB., Kok K., Krantz ID., Kuhn RM., Lee C., Ostell JM., Rosenberg C., Scherer SW., Spinner NB., 485 Stavropoulos DJ., Tepperberg JH., Thorland EC., Vermeesch JR., Waggoner DJ., Watson MS., 486 Martin CL., Ledbetter DH. 2010. Consensus Statement: Chromosomal Microarray Is a First-Tier 487 Clinical Diagnostic Test for Individuals with Developmental Disabilities or Congenital 488 Anomalies. The American Journal of Human Genetics 86:749-764 DOI:

489 10.1016/j.ajhg.2010.04.006.

490 
491 Mills RE., Walter K., Stewart C., Handsaker RE., Chen K., Alkan C., Abyzov A., Yoon SC., Ye K.,

492 Cheetham RK., Chinwalla A., Conrad DF., Fu Y., Grubert F., Hajirasouliha I., Hormozdiari F.,

493 lakoucheva LM., Iqbal Z., Kang S., Kidd JM., Konkel MK., Korn J., Khurana E., Kural D., Lam HYK.,

494 Leng J., Li R., Li Y., Lin C-Y., Luo R., Mu XJ., Nemesh J., Peckham HE., Rausch T., Scally A., Shi X.,

495 Stromberg MP., Stütz AM., Urban AE., Walker JA., Wu J., Zhang Y., Zhang ZD., Batzer MA., Ding

496 L., Marth GT., McVean G., Sebat J., Snyder M., Wang J., Ye K., Eichler EE., Gerstein MB., Hurles

497 ME., Lee C., McCarroll SA., Korbel JO. 2011. Mapping copy number variation by population-scale 498 genome sequencing. Nature 470:59-65 DOI: 10.1038/nature09708.

500 Nakanishi M., Deardorff MA., Clark D., Levy SE., Krantz I., Pipan M. 2012. Investigation of autistic

501 features among individuals with mild to moderate Cornelia de Lange syndrome. American Journal 502 of Medical Genetics Part A 158A:1841-1847 DOI: 10.1002/ajmg.a.34014.

503

504 Nava C., Keren B., Mignot C., Rastetter A., Chantot-Bastaraud S., Faudet A., Fonteneau E., Amiet

505 C., Laurent C., Jacquette A., Whalen S., Afenjar A., Périsse D., Doummar D., Dorison N., Leboyer

506 M., Siffroi J-P., Cohen D., Brice A., Héron D., Depienne C. 2013. Prospective diagnostic analysis of

507 copy number variants using SNP microarrays in individuals with autism spectrum

508 disorders. European Journal of Human Genetics 22:71-78 DOI: 10.1038/ejhg.2013.88.

509

510 Nemirovsky SI., Córdoba M., Zaiat JJ., Completa SP., Vega PA., González-Morón D., Medina NM.,

511 Fabbro M., Romero S., Brun B., Revale S., Ogara MF., Pecci A., Marti M., Vazquez M., Turjanski A.,

512 Kauffman MA., Hu VW. 2015. Whole Genome Sequencing Reveals a De Novo SHANK3 Mutation 
513 in Familial Autism Spectrum Disorder. PLOS ONE 10:e0116358 DOI:

514 10.1371/journal.pone.0116358.

515

516 Schaaf CP., Sabo A., Sakai Y., Crosby J., Muzny D., Hawes A., Lewis L., Akbar H., Varghese R.,

517 Boerwinkle E., Gibbs RA., Zoghbi HY. 2011. Oligogenic heterozygosity in individuals with high-

518 functioning autism spectrum disorders. Human Molecular Genetics 20:3366-3375 DOI:

$51910.1093 / \mathrm{hmg} / \mathrm{ddr} 243$.

520

521 Schaefer GB., Mendelsohn NJ. 2013. Clinical genetics evaluation in identifying the etiology of

522 autism spectrum disorders: 2013 guideline revisions. Genetics in Medicine 15:399-407 DOI:

523 10.1038/gim.2013.32.

524

525 Schaefer G. 2016. Clinical Genetic Aspects of Autism Spectrum Disorders. International Journal of

526 Molecular Sciences 17:180 DOI: 10.3390/ijms17020180.

527

528 Scheuerle A., Wilson K. 2011. PARK2 copy number aberrations in two children presenting with

529 autism spectrum disorder: Further support of an association and possible evidence for a new

530 microdeletion/microduplication syndrome. American Journal of Medical Genetics Part B:

531 Neuropsychiatric Genetics 156:413-420 DOI: 10.1002/ajmg.b.31176.

532

533 Shen Y., Dies KA., Holm IA., Bridgemohan C., Sobeih MM., Caronna EB., Miller KJ., Frazier JA.,

534 Silverstein I., Picker J., Weissman L., Raffalli P., Jeste S., Demmer LA., Peters HK., Brewster SJ., 
535 Kowalczyk SJ., Rosen-Sheidley B., McGowan C., Duda AW., Lincoln SA., Lowe KR., Schonwald A.,

536 Robbins M., Hisama F., Wolff R., Becker R., Nasir R., Urion DK., Milunsky JM., Rappaport L., Gusella

537 JF., Walsh CA., Wu B-L., Miller DT. 2010. Clinical Genetic Testing for Patients With Autism

538 Spectrum Disorders. Pediatrics 125:e727-e735 DOI: 10.1542/peds.2009-1684.

539

540 Shi L. 2014. Dock protein family in brain development and neurological disease. Communicative

541 \& Integrative Biology 6:e26839 DOI: 10.4161/cib.26839.

542

543 Solomon NM. 2004. Array comparative genomic hybridisation analysis of boys with $\mathrm{X}$ linked

544 hypopituitarism identifies a 3.9 Mb duplicated critical region at Xq27 containing SOX3. Journal of 545 Medical Genetics 41:669-678 DOI: 10.1136/jmg.2003.016949.

546

547 South ST., Lee C., Lamb AN., Higgins AW., Kearney HM. 2013. ACMG Standards and Guidelines

548 for constitutional cytogenomic microarray analysis, including postnatal and prenatal 549 applications: revision 2013. Genetics in Medicine 15:901-909 DOI: 10.1038/gim.2013.129.

550

551 Stankiewicz P., Thiele H., Schlicker M., Cseke-Friedrich A., Bartel-Friedrich S., Yatsenko SA., Lupski

552 JR., Hansmann I. 2005. Duplication of Xq26.2-q27.1, includingSOX3, in a mother and daughter 553 with short stature and dyslalia. American Journal of Medical Genetics Part A 138A:11-17 DOI:

554 10.1002/ajmg.a.30910.

555 
556 Starkstein S., Gellar S., Parlier M., Payne L., Piven J. 2015. High rates of parkinsonism in adults

557 with autism. Journal of Neurodevelopmental Disorders 7:29 DOI: 10.1186/s11689-015-9125-6.

558

559 de la Torre-Ubieta L., Won H., Stein JL., Geschwind DH. 2016. Advancing the understanding of 560 autism disease mechanisms through genetics. Nature Medicine 22:345-361 DOI: $561 \quad 10.1038 / \mathrm{nm} .4071$.

562

563 UniProt: the universal protein knowledgebase. The UniProt Consortium. 2017. www.uniprot.org.

564 Accessed 21 January 2017.

565

566 Wang J-C., Mahon LW., Ross LP., Anguiano A., Owen R., Boyar FZ. 2016. Enrichment of small 567 pathogenic deletions at chromosome 9p24.3 and 9q34.3 involving DOCK8, KANK1, EHMT1 genes

568 identified by using high-resolution oligonucleotide-single nucleotide polymorphism array 569 analysis. Molecular Cytogenetics 9:82. DOI: 10.1186/s13039-016-0291-3.

570

571 Yin C-L., Chen H-I., Li L-H., Chien Y-L., Liao H-M., Chou MC., Chou W-J., Tsai W-C., Chiu Y-N., Wu 572 Y-Y., Lo C-Z., Wu J-Y., Chen Y-T., Gau SS-F. 2016. Genome-wide analysis of copy number variations 573 identifies PARK2 as a candidate gene for autism spectrum disorder. Molecular Autism 7:23 DOI: 574 10.1186/s13229-016-0087-7. 
576 Zhang Q., Davis JC., Lamborn IT., Freeman AF., Jing H., Favreau AJ., Matthews HF., Davis J., Turner

577 ML., Uzel G., Holland SM., Su HC. 2009. Combined Immunodeficiency Associated with DOCK8

578 Mutations. New England Journal of Medicine 361:2046-2055 DOI: 10.1056/NEJMoa0905506.

579

580 Zhou Y. 2006. Simplified Molecular Diagnosis of Fragile X Syndrome by Fluorescent Methylation-

581 Specific PCR and GeneScan Analysis. Clinical Chemistry 52:1492-1500 DOI:

582 10.1373/clinchem.2006.068593.

583

584 Zimprich A., Benet-Pagès A., Struhal W., Graf E., Eck S H., Offman M N., Haubenberger D., 585 Spielberger S., Schulte E C., Lichtner P., Rossle S C., Klopp N., Wolf E., Seppi K., Pirker W., 586 Presslauer S., Mollenhauer B., Katzenschlager R., Foki T., Hotzy C., Reinthaler E., Harutyunyan A., 587 Kralovics R., Peters A., Zimprich F., Brücke T., Poewe W., Auff E., Trenkwalder C., Rost B., 588 Ransmayr G., Winkelmann J., Meitinger T., Strom T M. 2011. A Mutation in VPS35, Encoding a 589 Subunit of the Retromer Complex, Causes Late-Onset Parkinson Disease. The American Journal 590 of Human Genetics 89:168-175 DOI: 10.1016/j.ajhg.2011.06.008. 


\section{Table 1 (on next page)}

Detection rates of rare CNV in patients with ASD for different methods

* detected by karyotyping, MLPA and CMA: r(22)(q13.3)

** detected by MLPA and CMA

***15 confirmed by CMA, 3 not confirmed

**** CNVs of coding region with frequency $<1 \%$ in population

2a t(10;11)(q26;p13)pat; inv(Y)(p11.2q11.23) 


\begin{tabular}{|c|c|c|c|c|c|c|c|c|c|c|c|}
\hline Method & pathogenic CNV & $\%$ & $\begin{array}{l}\text { Vous likely } \\
\text { pathogenic }\end{array}$ & $\%$ & VOUS uncertain & $\%$ & $\begin{array}{l}\text { Vous likely } \\
\text { benign }\end{array}$ & $\%$ & $\begin{array}{l}\text { patients with } \\
\text { rare variants } \\
\text { totally }\end{array}$ & $\%$ & negative \\
\hline karyo & 1 & 1.09 & 0 & 0 & 0 & 0 & 2 & 2.17 & $2^{a}+1^{*}$ & 3.26 & 89 \\
\hline FMR1 & 1 & 1.09 & - & - & - & - & - & - & 1 & 1.09 & 91 \\
\hline MLPA & $7+1^{*}$ & 8.69 & 4 & 4.35 & 0 & 0 & 6 & 6.52 & $18^{* * *}$ & 19.57 & 74 \\
\hline \multirow[t]{2}{*}{ CMA } & $7+1^{*}$ & 8.69 & $8+4 * *$ & 13.04 & 6 & 6.52 & $26+3^{* *}$ & 31.52 & $55^{* * * *}$ & 59.78 & 37 \\
\hline & 9 & 9.78 & 12 & 13.04 & 6 & 6.52 & 34 & 36.96 & 61 & 66.3 & 31 \\
\hline
\end{tabular}




\section{Table 2 (on next page)}

The list of detected CNV

$*_{\text {not in DGV }}$

**patient with FMR1 mutation

***patients with multiple CNV 


\section{A. Pathogenic CNV}

\begin{tabular}{|c|c|c|c|c|c|c|c|c|}
\hline $\begin{array}{l}\text { Patient } \\
\text { ID }\end{array}$ & Band & CNV status & $\begin{array}{c}\text { Region } \\
\text { GRCh37/hg19 } \\
\end{array}$ & $\begin{array}{l}\text { Lengt } \\
\mathrm{h}(\mathrm{kb})\end{array}$ & Inheritance & $\underset{r}{\text { Gende }}$ & Method of detection & $\begin{array}{c}\text { Syndrome } \\
\text { (phenotype MIM } \\
\text { number) }\end{array}$ \\
\hline D980/11 & $1 q 21.1-q 21.2$ & gain & $146476526-147825662$ & 1349 & de novo & $\mathrm{F}$ & MLPA(P297), CMA & dup 1q21.1(612475) \\
\hline \multicolumn{9}{|l|}{ D1277/0 } \\
\hline 8 & $7 q 11.22$ & loss & 72701018-74143060 & 1442 & de novo & M & MLPA(P245), CMA & WBS(194050) \\
\hline $\begin{array}{c}\text { D1522/1 } \\
6\end{array}$ & $15 q 11.2-q 13.1$ & gain & 20737094-31293264 & 10556 & $\begin{array}{c}\text { NA } \\
\text { (maternal } \\
\text { excluded) }\end{array}$ & M & $\begin{array}{l}\text { MLPA(P297,P343, } \\
\text { P070,P036, P245), } \\
\text { CMA }\end{array}$ & $\begin{array}{c}\text { dup } \\
15 q 11 q 13(608636)\end{array}$ \\
\hline D731/15 & $16 p 11.2$ & loss & 29432212-30190029 & 758 & paternal & M & $\begin{array}{c}\text { MLPA(P297,P343), } \\
\text { CMA }\end{array}$ & del 16p11.2 (611913) \\
\hline D767/14 & $16 p 11.2$ & gain & $29600878-30177240$ & 576 & paternal & M & $\begin{array}{c}\text { MLPA(P297,P343) } \\
\text { CMA }\end{array}$ & $\begin{array}{l}\text { dup 16p11.2 } \\
\text { (614671) }\end{array}$ \\
\hline \multicolumn{9}{|l|}{ D1981/1 } \\
\hline 2 & $22 q 11.21$ & loss & $20733667-21460220$ & 727 & NA & $M$ & MLPA(P245),CMA & del 22q11 (192430) \\
\hline $1764 / 16$ & $22 q 13.31-q 13.33$ & loss & $47349588-51197838$ & 3848 & de novo & $\mathrm{F}$ & $\begin{array}{c}\text { MLPA(P070,P036,P343 } \\
\text {,P245), karyo } \\
\text { r(22)(q13.3), CMA }\end{array}$ & $\begin{array}{l}\text { Phelan-McDermid sy } \\
(606230)\end{array}$ \\
\hline $770 / 16$ & Xp21.1-q21.2 & loss & $31518523-31948537$ & 430 & NA & M & MLPA(P245),CMA & BMD (300376) \\
\hline
\end{tabular}


B. VOUS - likely pathogenic CNV

\begin{tabular}{|c|c|c|c|c|c|c|c|c|}
\hline $\begin{array}{l}\text { Patient } \\
\text { ID }\end{array}$ & Band & $\begin{array}{l}\text { CNV } \\
\text { status }\end{array}$ & $\begin{array}{c}\text { Region } \\
\text { GRCh37/hg19 }\end{array}$ & $\begin{array}{l}\text { Length } \\
\text { (kb) }\end{array}$ & Inheritance & Gender & Method of detection & Gene of interest \\
\hline D1377/15*** & $1 q 42.2$ & gain & $231712603-231816159$ & 104 & NA & M & CMA & DISC1 \\
\hline D1377/15*** & $10 q 21.3$ & loss & 68312378-68445989 & 134 & & M & CMA & CTNNA3 \\
\hline $\mathrm{D} 1377 / 15^{* * *}$ & $8 p 23.2$ & loss & $3879391-4100961$ & 222 & NA & M & CMA & CSMD1 \\
\hline D357/12 & $2 \mathrm{p} 16.3$ & loss & $50943528-51041472$ & 98 & maternal & M & CMA & NRXN1 \\
\hline D1320/14 & $6 q 26$ & loss & $162631070-162982289$ & 351 & paternal & $M$ & CMA & PARK2 \\
\hline D1123/15 & $6 q 26$ & gain & $162716322-162912832$ & 197 & NA & $M$ & CMA & PARK2 \\
\hline D714/10 & $9 p 24.3$ & gain & $1-271132$ & 271 & NA & M & CMA & DOCK8 \\
\hline $\mathrm{D} 684 / 13$ & $9 p 24.3$ & gain & 203861-398865 & 195 & NA & M & CMA, MLPA (P070) & DOCK8 \\
\hline D1748/15 & $9 p 24.3$ & gain & $271533-440683$ & 169 & paternal & $M$ & CMA, MLPA (P070) & DOCK8 \\
\hline $840 / 15$ & $16 p 13.3$ & loss & $7212403-7459707$ & 247 & NA & $M$ & CMA & RBFOX1 \\
\hline D1327/13 & $20 \mathrm{p} 12.1$ & loss & $14806577-15042599$ & 236 & NA & $\mathrm{F}$ & CMA & MACROD2 \\
\hline $\mathrm{D} 781 / 16$ & Xp22.11p21.3 & gain & $23794728-28429500$ & 4635 & de novo & $\mathrm{F}$ & $\begin{array}{c}\text { MLPA (P106-MRX), } \\
\text { CMA }\end{array}$ & APOO,POLA1,ARX* \\
\hline D1094/16** & Xp22.33 & gain & $1755742-1821317$ & 66 & NA & M & CMA & ASMT* \\
\hline D1194/15 & Xp11.4 & gain & $38486618-38634614$ & 148 & NA & $\mathrm{F}$ & $\begin{array}{c}\text { MLPA (P106-MRX), } \\
\text { CMA }\end{array}$ & TSPAN7 \\
\hline D1190/16*** & Xq27.3 & gain & $138614319-143156110$ & 4541 & NA & $M$ & CMA & $\begin{array}{l}\text { SOX3, F9, ATP11C, } \\
\text { CDR1, LDOC1* }\end{array}$ \\
\hline
\end{tabular}

C. VOUS - uncertain CNV 


\begin{tabular}{|c|c|c|c|c|c|c|c|c|}
\hline Patient ID & Band & CNV status & $\begin{array}{c}\text { Region } \\
\text { GRCh37/hg19 }\end{array}$ & $\begin{array}{l}\text { Length } \\
\text { (kb) }\end{array}$ & Inheritance & Gender & $\begin{array}{l}\text { Method of } \\
\text { detection }\end{array}$ & Gene of interest \\
\hline D1474/15 & $2 \mathrm{p} 12$ & loss & $80271129-80377518$ & 106 & NA & $\mathrm{F}$ & CMA & CTNNA2 \\
\hline $\mathrm{D} 538 / 16$ & $2 q 13$ & loss & $110874326-111365996$ & 492 & maternal & $\mathrm{F}$ & CMA & NPHP1 \\
\hline D1471/14 & $6 q 22.33$ & loss & $128633613-128811348$ & 178 & NA & $\mathrm{M}$ & CMA & PTPRK* \\
\hline D970/14 & $9 q 33$ & gain & $124034190-12444190$ & 408 & NA & & CMA & $\begin{array}{c}\text { GSN, STOM, DAB2IP, } \\
\text { EPB72* }\end{array}$ \\
\hline $\mathrm{D} 1190 / 16^{* * *}$ & $\begin{array}{c}\text { 11q14.3- } \\
\text { q21 }\end{array}$ & gain & $90076743-93118662$ & 3040 & NA & $M$ & CMA & $\begin{array}{l}\text { MTNR1B (melatonin } \\
\text { receptor), FAT3, } \\
\text { SLC36A4* }\end{array}$ \\
\hline D1190/16*** & $5 q 32.2$ & gain & $174151663-174157517$ & 5 & NA & $M$ & $\mathrm{CMA}$ & MSX2 \\
\hline $\mathrm{D} 1377 / 15^{* * *}$ & $16 q 11.2$ & gain & $46600773-46830637$ & 230 & NA & $M$ & CMA & $\begin{array}{c}\text { MYLK3, ORC6, SHCBP1, } \\
\text { VPS35 }\end{array}$ \\
\hline D1116/12 & $16 \mathrm{p} 12.2$ & gain & 21591157-21951415 & 360 & $\begin{array}{l}\text { NA(maternal } \\
\text { excluded) }\end{array}$ & $M$ & CMA & $\begin{array}{l}\text { OTOA, METTL9, IGSF6 } \\
\text { GRN, ITGA2B, SLC4A1, } \\
\text { ASB16, GPATCH8, } \\
\text { RUNDC3A, SLC25A39, }\end{array}$ \\
\hline D2121/13 & $17 q 21.32$ & gain & $42212006-42542693$ & 331 & NA & $\mathrm{F}$ & CMA & UBTF, SHC1P2* \\
\hline D1094/16** & Xp11.22 & gain & 53444924-53459515 & 15 & NA & $\mathrm{M}$ & CMA & SMC1A, HSD17B10 \\
\hline
\end{tabular}




\section{Table 3 (on next page)}

Clinical characterisation of the patients with DOCK8 gains.

*Glessner et al., 2017; CC - corpus callosum 


\begin{tabular}{|c|c|c|c|c|c|c|c|c|}
\hline \multirow{3}{*}{$\begin{array}{c}\text { resource } \\
\text { GRCh37/hg19 } \\
\text { interval of assesed } \\
\text { variants } \\
\end{array}$} & \multirow[b]{2}{*}{ ISCA } & \multirow[b]{2}{*}{ Decipher } & \multirow{3}{*}{$\begin{array}{c}\text { Krgovic } \\
\text { 204193-271316 } \\
\end{array}$} & \multirow{3}{*}{$\mathbf{N}$} & \multirow{3}{*}{$\%$} & \multicolumn{3}{|c|}{ Our patients } \\
\hline & & & & & & D714/1 & D684/13 & D1748/15 \\
\hline & $52389-416351$ & 41587-489842 & & & & $1-271132$ & 203861-398865 & 271533-440683 \\
\hline \multicolumn{9}{|l|}{ number of assesed } \\
\hline cases & 37 & 19 & 2 & 58 & 100.0 & & & \\
\hline DD & 8 & 4 & 1 & 13 & 22.41 & + & - & - \\
\hline ASD* & 3 & 6 & 1 & 10 & 17.24 & + & + & + \\
\hline ID & 1 & 6 & 1 & 8 & 13.79 & + & - & - \\
\hline behavioural abn. & 0 & 4 & 2 & 6 & 10.34 & - & - & - \\
\hline dysmorphic & 3 & 3 & 1 & 7 & 12.06 & + & - & - \\
\hline speech delay/disorder & 0 & 2 & 2 & 4 & 6.9 & + & + & + \\
\hline seizures & 2 & 2 & 0 & 4 & 6.9 & - & - & - \\
\hline ambiguous genitalia & 1 & 1 & 0 & 2 & 3.45 & - & - & - \\
\hline obesity & 0 & 2 & 0 & 2 & 3.45 & - & - & + \\
\hline sleep disturbance & 0 & 1 & 0 & 1 & 1.72 & - & - & + \\
\hline microcephaly & 0 & 0 & 1 & 1 & 1.72 & - & - & - \\
\hline dolichocephaly & 0 & 1 & 0 & 1 & 1.72 & - & - & - \\
\hline plagiocephaly & 0 & 1 & 0 & 1 & 1.72 & - & - & - \\
\hline craniosynostosis & 0 & 1 & 0 & 1 & 1.72 & - & - & - \\
\hline cardiac abnorm. & 1 & 0 & 0 & 1 & 1.72 & - & - & - \\
\hline short stature & 0 & 1 & 0 & 1 & 1.72 & - & - & - \\
\hline agenesis CC & 1 & 0 & 0 & 1 & 1.72 & - & - & - \\
\hline feeding problems & 0 & 1 & 0 & 1 & 1.72 & - & - & - \\
\hline undescended testes & 0 & 0 & 0 & 0 & 0 & + & - & + \\
\hline ADHD* & 0 & 0 & 0 & 0 & 0 & + & + & + \\
\hline hypacusis & 0 & 0 & 0 & 0 & 0 & - & + & + \\
\hline
\end{tabular}


Figure 1

Duplication of the gene DOCK8 in 3 unrelated patients.

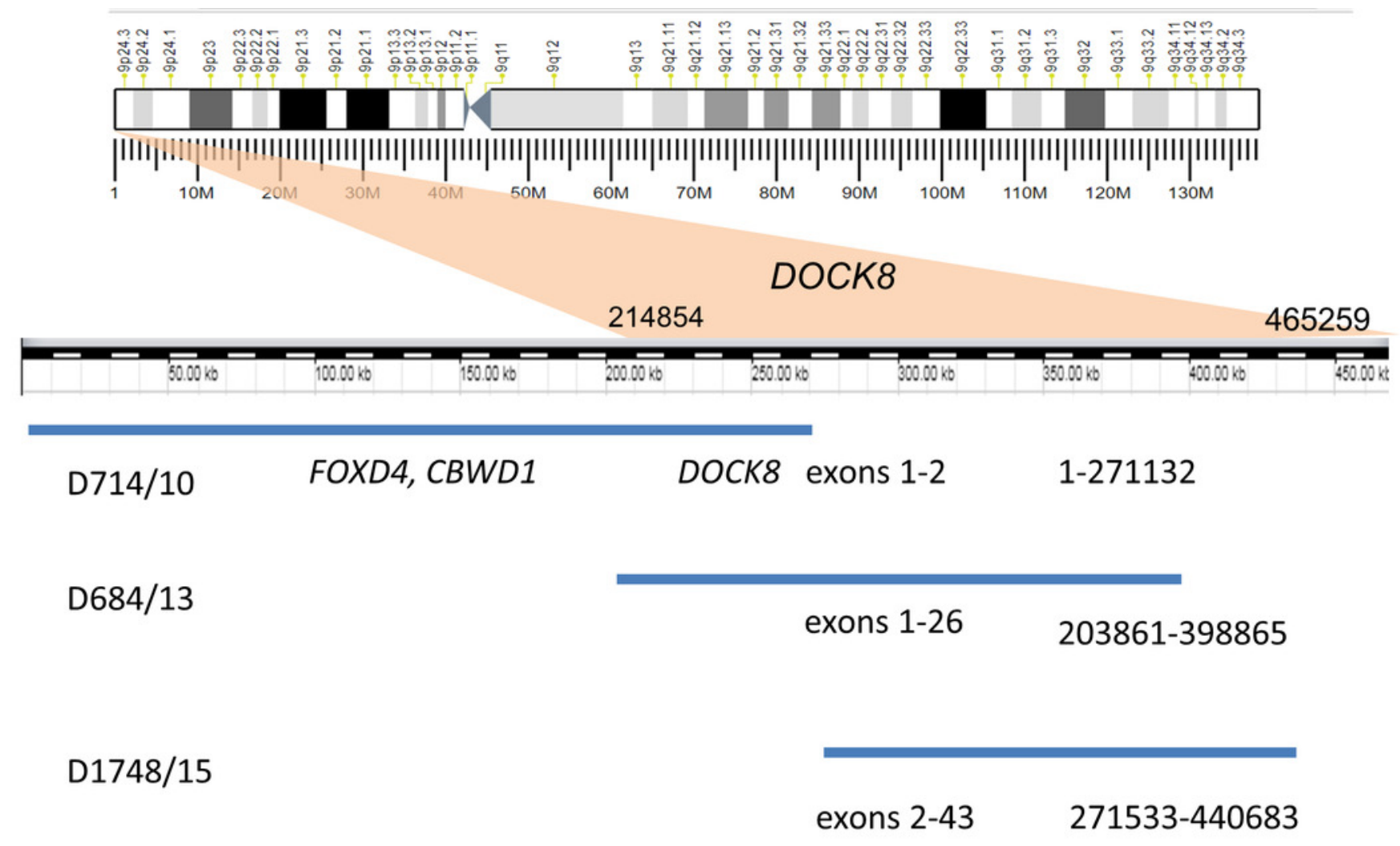


Figure 2

Segregation analysis for the family of a patient bearing a CNV causing loss of NRXN1.

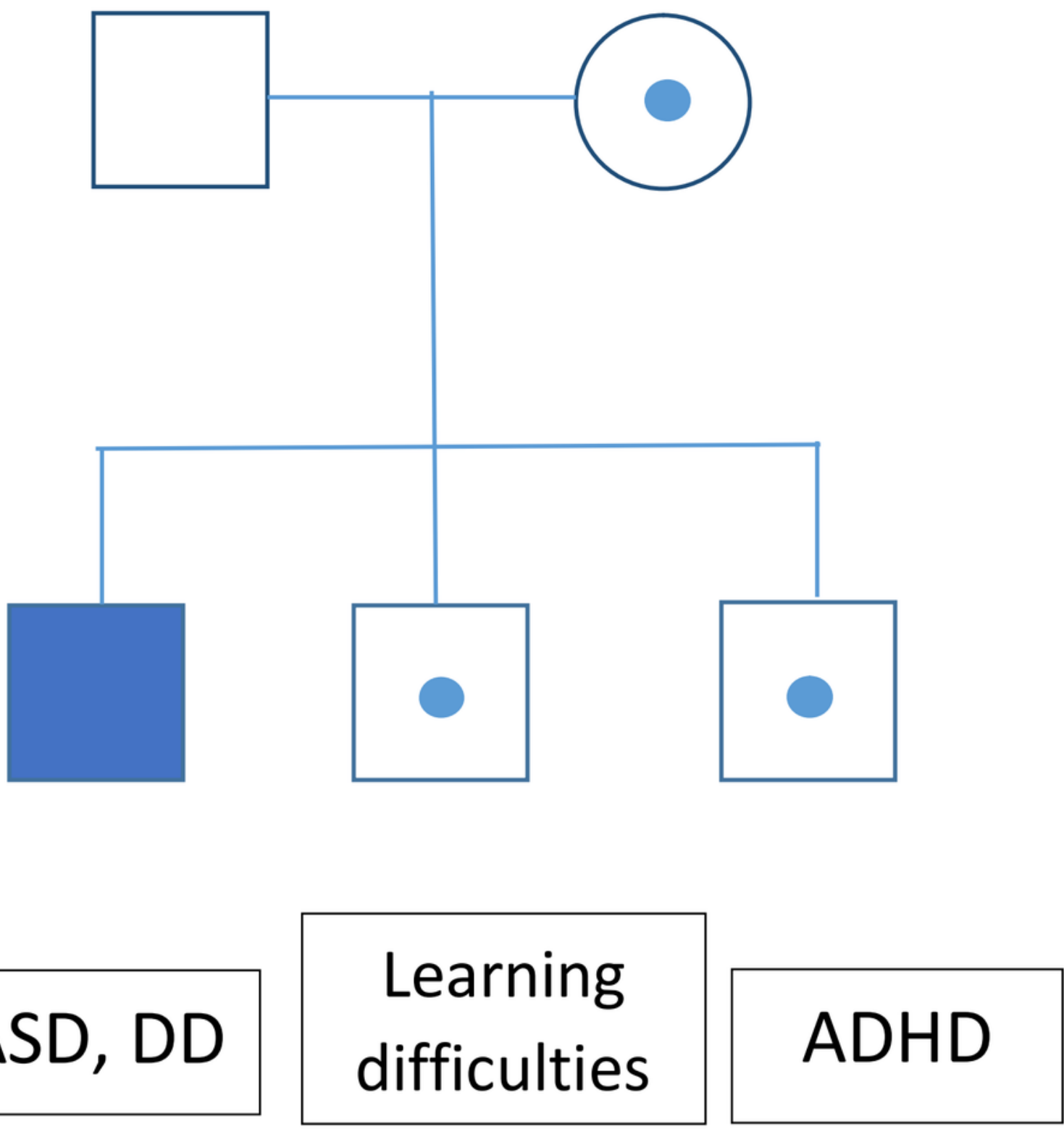

